\title{
Morphological characteristics of Talaromyces sp., Cladosporium sp. and Penicillium sp. as microfungi in biodegradation of oil sludge using scanning electron microscope (SEM)
}

\begin{abstract}
The microfungi Talaromyces sp., Cladosporium sp. and Penicillium sp. are able to produce biosurfactan and can degrade hydrocarbon compounds in oil sludge waste Oil sludge is one of the hazardous waste produced by the petroleum industry and categorized as hazardous and toxic waste category 1 , which means it could be acute for human being and the environment. The present study aims to demonstrate the differences in morphological characteristic of Talaromyces sp., Cladosporium sp. and Penicillium sp. in the medium containing/and without oil sludge as biodegrader of oil sludge. In this study, descriptive method was conducted to characterize the three of microfungal species morphologically with three stages: preparation, culture and morphological characterization of fungal hyphae with Scanning Electron Microscope (SEM) in two types of medium (with and without oil sludge). The SEM observations demonstrate changes in hypha morphology for the medium containing oil sludge treatment. Aggregation and changes in the structure of hyphae occurred. This changes covers the number of branches, shrinkage of size and cell walls, as well as cell lysis. The present work showed that the presence of oil sludge can change the morphological characteristics of microfungi compared to control, indicating the adaptation ability of these three microfungal species in degrading oil sludge waste.
\end{abstract}

Keywords: oil sludge, scanning electron microscope (SEM), Talaromyces sp., Cladosporium sp., Penicillium sp.
Volume 6 Issue 6 - 2018

\author{
Nia Rossiana, Betty Mayawatie, Mohammad \\ Raihan Amin, Eka Fitriani, Betrik \\ Biology Department, Universitas Padjadjaran, Indonesia
}

Correspondence: Nia Rossiana, Biology Department, Universitas Padjadjaran, Jl. Raya Bandung Sumedang KM.2I, Kab. Sumedang 45363, Indonesia, Email niarossiana@yahoo.com

Received: November 20, 2018 | Published: December 20, 2018

\section{Introduction}

Oil sludge waste is produced from the petroleum industries and categorized as the hazardous and toxic waste that must be managed biologically using bioremediation (Ministry of Environment Republic of Indonesia No. 128/2003). The national authorities No. 101/2014 stated that oil sludge is categorized into the hazardous and toxic waste with code A307-1, which means that it has an actute impact on humans and the surroundings. Several researchers have developped the variety of microorganisms that possibly used as bioremediation agents for oil sludge waste, for instance fungi. To date, many researchers studied the significancy of fungi to degrade the hydrocarbons due to the ability of fungal hyphae to produce hydrolytic enzyme that can penetrate the substrate and reduce hydrocarbon pollutants in contaminated soils. The role of fungi in biodegradation of petroleum products has been extensively studied and several genera of have been identified as bioremediation agents. For instance, the genus Cladosporium. In vitro test of Talaromyces sp., Cladosporium sp., and Penicillium sp. as the potential bioremediation agents has been conducted by Fiandisty. ${ }^{2}$ The author demonstrated that these three genera can produce biosurfactan in oil spreading assay test and are able to degrade hydrocarbon compounds. Although these genera are confirmed for their ability in producing biosurfactant and degrading the hydrocarbon in oil sludge waste, a clear explanation in morphological change due to the presence of oil sludge medium has not been documented.

The purpose of this present study was to determine the differences in morphological characteristics of fungal hyphae of Talaromyces sp., Cladosporium sp., and Penicillium sp. in the medium containing oil sludge and without oil sludge (control), as bioremediation agents, using the Scanning Electron Microscope (SEM).

\section{Materials and methods}

The present work was conducted using descriptive method on the difference of morphological traits of hyphae from Talaromyces sp., Cladosporium sp., and Penicillium sp. in two types of medium, with(treatment) and without the oil sludge (control) in $48 \mathrm{~h}$ and $120 \mathrm{~h}$ incubation time using the SEM. This study was performed in three steps: preparation, culture of fungi and morphological characterization.

\section{Sample preparation}

All materials used were sterilized using autoclave. The material preparation was carried out by rejuvenating the fungal pure culture on the slant type medium using (Potatoes Dextrose Agar) PDA medium and culture medium creation.

Culture medium preparation was started by preparing the $20 \%$ Potatoes Dextrose Broth (PDB) that was combined with $0.5 \%$ NPK, $2 \%$ succrose and $0.9 \% \mathrm{NaCl}$ as much as $73 \%$ from the volume total of the planned medium that will be prepared for the control medium. As for the oil sludge medium, the $2 \%$ succrose was replaced with $2 \%$ oil sludge. After, each medium was placed into the erlenmeyer tubes and clogged with cotton before sterilization in autoclave.

\section{Microfungal culture}

The microfungal culture was started by preparing the inoculum starter. Briefly, fungal mycelium was dredged using the ose, 
resuspended into erlenmeyer tube containing $100 \mathrm{ml}$ of $0.9 \% \mathrm{NaCl}$ sterile. Afterwards, a total of $1 \mathrm{ml}$ of $0.1 \%$ tween solution was added into the erlenmenyer tube. Then, erlenmeyer tube was placed into the shaker for $5 \mathrm{~min}$ at $140 \mathrm{rpm}$ to homogenize the starter.

The microfungal culture was carried out by using a liquid culture in erlenmeyer tube. Culture was started by preparing the culture medium in erlenmeyer tube, then the microfungal starter was inserted into the tube containing culture medium. Afterwards, the tube was placed into the shaker at 140rpm to homogenized the sample and incubated at room temperature $\left(27^{\circ} \mathrm{C}\right)$ for $5 \mathrm{~d}$.

\section{Microfungal characterization}

The characterization of microfungal samples were performed by constant observation of hyphae morphology on 48 and $120 \mathrm{~h}$ of incubation time using the Scanning Electron Microscope (SEM).

\section{Results and discussion}

Differences in hyphae morphological characteristics were found in all three microfungal genera, indicating dissimilarity in morphological profile between the hyphae in control and treatment. The observation on morphological characteristic of Talaromyces sp. change after incubated in $2 \%$ of oil sludge medium compared to that of control. Aggregation and changes in hypha structure were observed, such as shrinkage in size of hypha and cell walls as well as cell lysis. This is perhaps due to the presence of oil sludge in the medium. The oil sludge generally contains hydrocarbon that may affectthe morphological growth of Talaromyces sp.. No significant dissimilarities were found in the morphological traits of Talaromyces $\mathrm{sp}$. in control medium, where the shrinkage in hypha was absence and no cell lysis was observed. In addition, a significant difference can be observed from the size of hyphae. Reduction in hyphae size in the culture containing oil sludge is presented in Figure 1. The mean width of hyphae in treatment was $4 \mu \mathrm{m}$, whereas in the control was $6 \mu \mathrm{m}$ at 1000x of magnification in SEM.

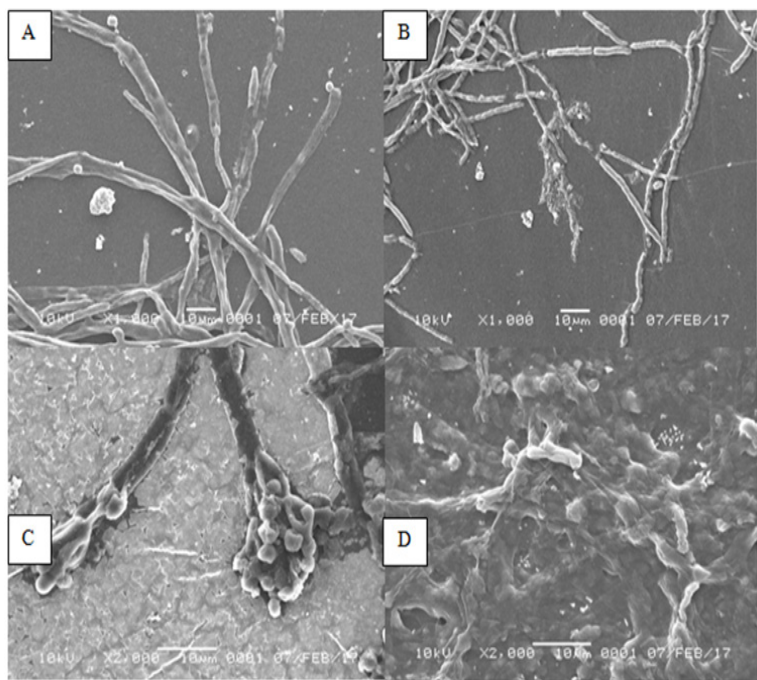

Figure I Morphology of Talaromyces sp. observed by using Scanning Electron Microscope (SEM). (A) Talaromyces sp. grows in the medium without oil sludge after $2 \mathrm{~d}$ of incubation. (B) Talaromyces sp. grows in the oil sludge-containing medium after $2 \mathrm{~d}$ of incubation. (C) Talaromyces sp. grows in the medium without oil sludge after $5 \mathrm{~d}$ of incubation. (D) Talaromyces sp. grows in the oil sludge-containing medium after $5 \mathrm{~d}$ of incubation.
The cultured microfungal Talaromyces sp. in the medium containing oil sludge $2 \%$ had significant difference in terms of morphology compared to control. As for control, the morphology of conidia was very clear and hyphae appeared to be normal, while severe damage was found in the treatment, such as invisible form of hyphae, cell lysis and damage on the cell wall of hyphae thus hyphae wall was invisible as well as significant differences in hyphae size. Morphological observations using SEM at 2000x magnification revealed that the difference in size of hyphae between the two treatments was clearly distinct.

The hyphae of Cladosporium sp. in control medium was normal. Additionally, hyphae have clearly visible with normal size, normal branching with flat shape form and their surface appeared to be concave inwards. In contrast, hypha of Cladosporium sp. after $2 \mathrm{~d}$ of exposure to oil sludge was appeared to be aggregated forming hooks. Moreover, hyphae shrinkage was observed and oil sludge was attached to the surface of the hyphae. At similar magnification (1000x), distinct difference on the average of hyphae between the normal and treatment medium was observed. The hyphae in control medium was $33 \%$ wider than that of treated medium.

No deformities in morphology was observed in the hyphae of Cladosporium sp. In the normal medium with $120 \mathrm{~h}(5 \mathrm{~d})$ of incubation (Figure 2). This can be observed from the uniformity in size of hyphae, flat shape, visible septa, no shrinkage of the cell wall, absence of cell lysis and no damage in hyphae. On the other hand, abnormal morphology was appeared on the hyphae of Cladosporium sp. grew on the oil sludge medium with $5 \mathrm{~d}$ of incubation. It was confirmed by the irregular shape of hyphae, aggregation and shrinkage in size of hyphae compared to the control. The hyphae were also covered by the oil sludge. The mean of hyphae of Cladosporium sp. in the medium containing oil sludge was $50 \%$ lower than that of control. It is hypothesized that the attachment of oil sludge to hyphae could inhibit the respiration and nutrients absorption. Therefore, the size of hyphae shrinking.

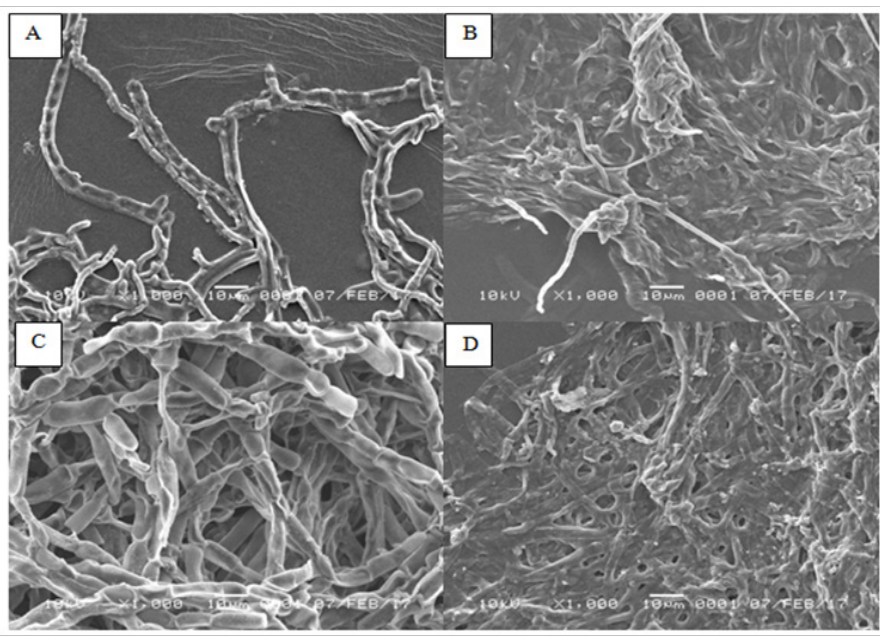

Figure 2 Morphology of Cladosporium sp. observed by using Scanning Electron Microscope (SEM). (A) Cladosporium sp. grows in the medium without oil sludge after $2 \mathrm{~d}$ of incubation. (B) Cladosporium sp. grows in the oil sludgecontaining medium after $2 \mathrm{~d}$ of incubation. (C) Cladosporium sp. grows in the medium without oil sludge after $5 \mathrm{~d}$ of incubation. (D) Cladosporium sp. grows in the oil sludge-containing medium after $5 \mathrm{~d}$ of incubation. 
In the control medium with $2 \mathrm{~d}$ of incubation, it was found that the hyphae of Penicillium sp. (Figure 3) were dense with more conidial branching. The shape of hypha is long and has septa with smooth surface structure. In contrast, the form of hyphae in Penicillium sp. in the oil sludge-containing medium was more dense and degraded into several fragments. Conidial and septa branching did not appear and tend to gather. Oil sludge attached on the surface of the hyphae. moreover, by using magnification of $6000 \mathrm{x}$, the mean diameter of Penicillium sp. in control medium was $1.7 \mu \mathrm{m}$, whereas the hyphae mean diameter in the treated medium was only $0.76 \mu \mathrm{m}$.

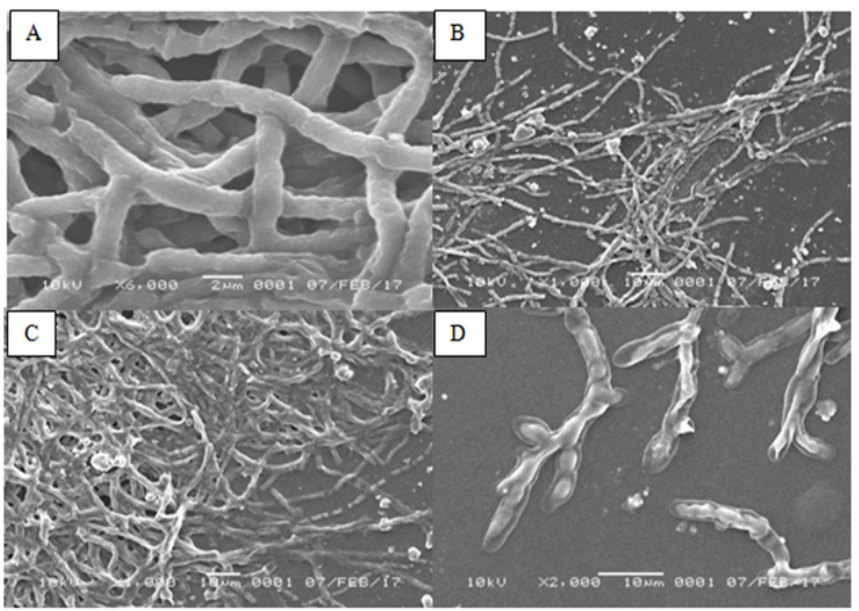

Figure 3 Morphology of Penicillium sp. observed by using Scanning Electron Microscope (SEM). (A) Penicillium sp. grows in the medium without oil sludge after $2 \mathrm{~d}$ of incubation. (B) Penicillium sp. grows in the oil sludge-containing medium after $2 \mathrm{~d}$ of incubation. (C) Penicillium sp. grows in the medium without oil sludge after $5 \mathrm{~d}$ of incubation. (D) Penicillium sp. grows in the oil sludge-containing medium after $5 \mathrm{~d}$ of incubation.

In the oil sludge medium with $5 \mathrm{~d}$ of incubation, the form of hyphae Penicillium sp. appeared to be airy. Obvious hyphae branching was found at the edge. The shape of hyphae intertwined loosely and appeared to be shrinking. Hyphae were damage and contracted. Additionally, the structure of Penicillium sp. was clearly observed with visible sterigmata, metula and conidia. The mean diameter size of hyphae was $2.5 \mu \mathrm{m}$ (magnification 2000x).

As for the medium without oil sludge, after $5 \mathrm{~d}$ of incubation, it appeared that the shape of hyphae of Penicillium sp. was very dense and piling up. Branching of hyphae was very clear with 1000x magnification, with diameter size $5.4 \mu \mathrm{m}$.

In general, the fungal hyphae undergo abnormality when degrading the oil sludge, both at 2 and $5 \mathrm{~d}$ of incubation time. Although hyphae have anomalies, their growth seems to be undisturbed. This can be observed when the hyphae density was still present in large numbers with excessive branching and appeared to continue to grow in aggregation.

The abnormality in form of hyphae could be due to their adaptation to the presence of oil sludge in the environment that may be toxic. In addition, the oil sludge that attached to the hyphae prevents the microfungi from breathing and absorbs nutrients from the PDB medium hence the fungal growth is inhibited. Indeed, oil sludge affects the condition of fungal hyphae but does not lethal. Fungi require a long time to degrade oil sludge, and take nutrients after degradation process is complete.

Previous studies demonstrated that Talaromyces sp., Cladosporium sp. and Penicillium sp. are able to degrade oil sludge. These results were also confirmed by Das \& Chandran, ${ }^{3}$ which found that microfungi from the genera Amorphoteca, Neosartorya, Talaromyces and Graphium as well as yeast, such as Candida, Yarrowia and Pichia that are isolated from the oil-contaminated soil were the potential candidates as bioagent for hydrocarbon degradation. Additionally, another study from Khalida ${ }^{4}$ revealed that $P$. chermesinum is able to reduce hydrocarbon compounds. This result was supported by the ability of this species that can grow in the medium containing oil sludge. This species can also reduce TPH level and can degrade PAH compounds. Another study from Fiandisty ${ }^{2}$ demonstrated that the utilization of single fungi isolate Cladosporium sp. and Talaromyces sp. have successfully produced biosurfactant and degraded hydrocarbon compounds in the medium containing $5 \%$ of oil sludge. This was also confirmed by the highest diminution of TPH level in the medium containing Talaromyces sp. (by 19.40\%), whereas the reduction in TPH level by Cladosporium sp. was $17.92 \%$ after 15 $\mathrm{d}$ of incubation.

The ability of fungi to degrade hydrocarbon compounds is due to their ability in producing enzyme. According to the Applied Biotreatment Association (1990), the ability of microorganisms biomass to degrade oil depends on the enzymes produced by hydrocarbon degrading species. The presence of high enzymatic capacity allows the community of microorganism to degrade complex hydrocarbon compounds. This capacity is to modify or decompose certain pollutants, such as petroleum, ${ }^{5}$ by using dioxygenase enzyme.

Dioxygenase enzyme is an enzyme that combines two oxygen atoms into the substrate. ${ }^{6}$ Microfungi organisms use this enzyme to break the aromatic ring that will then be used as their source of energy. This hypothese is in accordance with Whiteley \& Lee $^{7}$ that the activity of dioxygenase enzyme can destroy chemical bonds and allows the opening of the ring.

Decomposing process of hydrocarbon compounds by microorganisms starts with the attachment of microorganisms to the oil globula, followed by dissolving hydrocarbon compounds by surfactants produced by these microorganisms. Afterwards, these emulsified hydrocarbon compounds are then absorbed into the cell and decomposed through the catabolism. As for n-alkanes, this catabolism begins with the n-alkane hydroxylation that produces alkane-1-o1, which is then oxidized by the dehydrogenase enzyme and produces fatty acids. When the oxidation system of the hydrocarbon decomposing microorganisms can run optimally, the formed fatty acids will be completely broken down into energy, $\mathrm{H}_{2} \mathrm{O}$ and $\mathrm{CO}_{2}$ thorugh $\beta$-oxidation. ${ }^{8}$

\section{Conclusion}

The present study demonstrated distinct morphological characteristics in the three different genera of microfungi Talaromyces sp., Cladosporium sp. and Penicillium sp. when they are exposed in medium containing oil sludge as compared to the control medium. The main difference in morphological characteristics are the shrinkage on the size of hyphae, hyphae aggregation and cell lysis in hyphae. ${ }^{9-12}$ 


\section{Acknowledgments}

The authors gratefully acknowledge the chief of the Academic Leadership Grant (ALG) Prof. Dr. Poniah Andayaningsih, M.S. for her valuable supports in this project. The authors also wish to thank to the rector of Universitas Padjadjaran for financing this research through ALG granted to NR

\section{Conflicts of interest}

There is no conflicts of interest among the authors.

\section{References}

1. Venkatesagowda B, Ponugupaty E, Barbosa AM, et al. Diversity of plant oil seed-associated fungi isolated from seven oilbearing seeds and their potential for the production of lipolytic enzymes. World J Microbiol Biotechnol. 2012;28(1):71-80.

2. Fiandisty F, Wulandari AP, Rossiana N. Aktivitas Biosurfaktan dari Jamur Eksogenous Terhadap Penurunan Total Petroleum Hidrokarbon (TPH) Oil Sludge Asal Balongan. Jurnal Biotika. 2013;11(1).

3. Das N, Chandran P. Microbial Degradation of Petroleum Hydrocarbon Contaminants: An Overview. Biotechnology Research International. 2011:941810

4. Khalida, Mutia A. Profil Produksi Biomassa Penicillium Chermesinum Biourge. Terhadap Perubahan Kadar Tph Dan Senyawa PAH Oily Sludge. Universitas Padjadjaran. Bandung. 2016.
5. Peixoto RS, Vermelho AB, Rosado AS. Petroleum-Degrading Enzymes: Bioremediation and New Prospects. Enzyme Research. 2011:1-7.

6. Karigar CS, Rao SS. Role of Microbial Enzymes in the Bioremediation of Pollutants: A Review. Enzyme Research. 2011:1-11.

7. Whiteley CG, Lee DJ. Enzyme technology and biological remediation. Enzyme and Microbial Technology. 2006;38(3-4):291-316.

8. Godfrey T, dan Reichet J. Industrial Enzymology. The Application of Enzymes in Industry Stocon Press. New York; 1986.

9. Adekunle AA, Adebambo OA. Petroleum hydrocarbon utilization by fungi isolated from detarium senegalense (J.F Gmelin) Seeds. Journal of American Science. 2007;3(1):69-76.

10. Kementrian Lingkungan Hidup Nomor 128. Tentang: Tatacara dan Persyaratan Teknis Pengolahan Limbah Minyak Bumi dan Tanah Terkontaminasi Minyak Bumi Secara Biologis. Deputi MENLH Bidang Kebijakan dan Kelembagaan Lingkungan Hidup; 2003.

11. Lau NLA. Bioremediation of petroleum hydrocarbons in oil-contaminated beach sediments. Thesis. University of Singapore. Singapore; 2003.

12. https://kemenkopmk.go.id/sites/default/files/produkhukum/PP\%20 Nomor\%20101\%20Tahun\%202014 0.pdf 